\title{
Thesis Challenges for Arab PhD Candidates in English Medium of Instruction Context
}

\author{
Farida Aboud \\ $\mathrm{PhD}$ Candidate at Eastern Mediterranean University \\ E-mail: aboudfarida18@gmail.com \\ Rawan Alafeshat \\ PhD Candidate at Eastern Mediterranean University \\ E-mail: Rawan.alafeshat@emu.edu.tr \\ Ahmad Fawzi Shamsi \\ $\mathrm{PhD}$ Candidate at Eastern Mediterranean University \\ E-mail: a.fawzi.shamsi@gmail.com
}

Received: August 14, 2019

Accepted: Oct. 15, 2019

Published: November 1, 2019

doi:10.5296/jse.v9i4.15492

URL: https://doi.org/10.5296/jse.v9i4.15492

\begin{abstract}
The current study aimed to explore challenges faced by Arab doctoral students during their $\mathrm{PhD}$ program in an English Medium of Instruction (EMI) context. Besides, it intended to highlight the appropriate solutions provided by respondents to solve these challenges. Six Arab doctoral students ( 3 males and 3 females) were selected from different departments and Arab countries to participate in the study. The authors used semi-structured interviews as a qualitative method for obtaining specific responses by respondents. Later, the data were analyzed based on the content analysis technique. The findings showed different challenges facing Arab candidates during their program, specifically lacking experience in research methods, academic English, and publication. On the bases of the revealed results, the study provided implications, limitations, and future directions.
\end{abstract}

Keywords: Arab doctoral students, $\mathrm{PhD}$ challenges, EMI 


\section{Introduction}

Reaching advanced levels of education such as the doctoral degree might be a main purpose for many students in all over the world. According to Cambridge dictionary, $\mathrm{PhD}$ is an "abbreviation for doctor of philosophy: the highest college or university degree." Therefore, it does not represent a simple journey for the candidates; it requires varied skills such as time management, effective thought, productive mind, hardworking, etc. to accomplish this level of education successfully.

In some cases, students might leave their homelands seeking for academic knowledge, developmental experience, and high level of education. However, English as a Medium of Instruction (EMI) represents a serious challenge for $\mathrm{PhD}$ candidates. For example, Jomaa and Bidin (2017), found that Arab PhD students faced challenges in their academic writings because of their limited knowledge of the foreign language. As a result, the low level of proficiency prevents them from making a sufficient discussion in the target language (Al Fadda, 2012).

Other studies have asserted that international doctoral students might face additional challenges during their $\mathrm{PhD}$ program. For instance, Bireda (2015) found that less motivation, stress, anxiety, student-supervisor relationship, educational system, etc., were among the most problems noticed among the doctoral participants. Furthermore, candidates face challenges related to work process, experience, and available resources (Pyhältö et al., 2012). In addition, Mouton (2001) found that candidates encounter difficulties represented in mastering academic skills such as research methods and time management, and they might face problems related to funding, which affect their study, work, and life in general (Boyce et al., 2016; Walton et al., 2019). Students at the postgraduate level might also struggle due to cultural differences (Alavi, \& Mansor, 2011); as a result, they might have negative feelings such as depression, loneliness, isolation, etc. (Janta et al., 2014).

The current research, therefore, is significant as it investigates the fundamental problems facing Arab $\mathrm{PhD}$ students during their doctoral journey in the context of EMI at Eastern Mediterranean University (EMU) in North Cyprus. Besides, it highlights the suggestions provided by the respondents to solve these challenges. Consequently, the aim of the study is to explore the challenges facing Arab doctoral students during their program. Besides, it intends to provide the appropriate solutions for minimizing the degree of challenges appeared between the respondents at this level of education. To this end, the researchers attended to find answers for the two following questions

1. What are the challenges that face Arab doctoral students during their $\mathrm{PhD}$ program?

2. What are the possible solutions provided by Arab doctoral students to decrease the degree of these challenges?

The outcome of the study might contribute to enhancing the attention of the institutional policy in reconsidering the doctoral program in the light of solutions provided by the participants. Additionally, it might give a rise to curriculum designers to help the doctoral students in improving their academic skills. 


\section{Literature Review}

Apparently there are many challenges facing the doctoral students during their journey according to authors and scholars in varied fields of studies. However, the current study focused on presenting a brief and comprehensive review of challenges related to personal, institutional, and language challenges.

Doctoral students face personal challenges in their way to complete the program, and it might be different form one to another; the review highlighted the common problems among them. For example, candidates require professional skills to accomplish this level; a number of studies attended to find out basic competences required from those students to master at this educational level. Barrie (2004) carried out a qualitative study to explore the skills needed by the postgraduate students to succeed this level. Barrie provided different types of skills such as time management, language proficiency, and curriculum knowledge. According to Platow (2012) the mentioned competences contribute to helping students mastering the success at this degree. At the same vain, Odena and Burgess (2017) stated that time management skill was the key factor beyond developing students writing skills. Besides, Kalaleh et al (2014) found that candidates should develop competences, such technical skills, to obtain fruitful results in their study.

However, lacking such skills may lead to some problems as Lei and Hu (2019) suggest. Students experience some problems related to publication, such as their limited academic skills and research methods' skills (Bamgboje-Ayodele et al., 2016). Also, Jomaa and Bidin (2017) found that Arab PhD students face challenges in their academic writings because of their limited knowledge of the foreign language. As a result, the low level of proficiency prevents them from making a sufficient discussion in the target language (Al Fadda, 2012). Consequently, $\mathrm{PhD}$ candidates may encounter negative feelings such as stress (Al Fadda, 2012; Moate et al., 2019) and lack of motivation (Hwang et al., 2015). These negative emotions might force some of them to leave the doctoral program (Hunter \& Devine, 2016). On the other hand, Kakupa (2019) stated that students with advanced research skills experience high level of self-confidence and low level of anxiety.

Besides, studies asserted additional types of personal challenges that might affect the $\mathrm{PhD}$ students. For example, the study of Alavi and Mansor (2011) found that students at the doctoral level might struggle due to the cultural differences, which may cause depression, loneliness, and isolation (Janta et al, 2014). Therefore, Janta et al (2014) supposed that the organization should support the students through engaging them in different types of academic activities such as conferences, training programs, etc., to avoid the given above difficulties.

Previous studies illustrated that the educational organization or the institutional system might be considered as one of the key challenges facing the doctoral students. Also, it is seen as a significant factor affecting their study, success, and future career. Certainly, there are varied parties related to the organization, such as the advisor, who plays a considerable role in the doctoral student's life. In other words, the relationship between the $\mathrm{PhD}$ students and their supervisors is considered as a significant factor affecting their degree of success at this level (Nesterowicz et al., 2019). Previous studies asserted a number of advantages through the 
good relationship between the candidates and their instructors (Olive, 2019) such as completing an effective thesis, publishing a paper and other benefits (Duffy et al., 2019). However, maintaining a positive relationship between these parties requires specific criteria to be found; therefore, researchers from different domains are interested in studying the basic attributes that the supervisors should have at this level of education. Hyatt and Williams (2011) presented varied skills of a good supervisor, such acquiring the pedagogical knowledge related to the content and the research method experience. Another skills is presenting skills related to students such as the ability to guide, support, monitor, and encourage $\mathrm{PhD}$ candidates till the end of the program. All of the mentioned competences contribute to constructing a positive relationship with the students. In turn, good characters such as motivation, progress, self-confidence, and autonomy - play part in shaping the students' identity again during their PhD journey (Bireda, 2015; Wisker et al., 2010). Bireda (2015) found that her participants were, to some degree, satisfied with their supervisor; however, receiving a supervisor's feedback was one of their problems. Also, in a study conducted by Harman (2003), there are negative complains about the inability of meeting with their supervisors. Therefore, undesirable relationship could be existed between the student and their supervisors, which could lead to time wasting and failing in accomplishing this program (Jones, 2013). Therefore, Jones (2013) recommends students to select a professional supervisor for gaining more successful outcome.

At the same vein, the inflexibility of doctoral program, intensive exams, absences of support (Hwang et al., 2015), thesis writing (Moate et al., 2019), publishing (Lei \& Chuang, 2009), and limited resources accessibility (Warburton \& Macauley, 2014) are some of the difficulties found in the review related to institutional challenges. Therefore, Alkathiri and Olson (2018) suggested equipping students with adequate skills to meet the needs of the doctoral program. Also, the lack of developmental training programs could negatively influence the candidates' abilities to program accomplishment. Therefore, Hunter and Devine (2016) consider that developing students' skills, through such training programs, might contribute to increasing their productive outcomes. When the institution directs to provide conditions of high quality for the candidates, it contributes to obtaining a successful learner and effective outcome (Li \& Qi, 2019).

The financial support is considered as an influential factor impacting, negatively or positively, the journey of doctoral students. It might include varied types of support such as scholarship or research assistantship, and it contributes to influencing the consequence of the doctoral students during their study (Knight et al., 2018). Although in some cases the funding is obtainable, it is not adequate for some students to complete this degree (Boyce et al., 2016). According to Harman (2003), funding support reflected a serious problem for a number of national and international students. Bireda, (2015) and Pyhältö et al. (2012) confirmed that $\mathrm{PhD}$ students have not received a sufficient funding that supports their research process, work, etc. Platow (2012) states that there is a negative impact of limited funding on students' academic career and their productive capacity in completing their $\mathrm{PhD}$ programs. Sometimes, doctoral students might be forced to leave the program due to their inadequate financial situation (Aziato, 2015). Therefore, Knight et al (2018) recommended the responsible 
institution to provide students a kind of funding support equal to the doctoral program's needs. Also, Boyce et al (2016) produced another solution based on providing funding in terms of non-working doctoral students in that enables them to accomplish their journey in a short period of time and produce a productive result in their researches.

Another major challenge of non-native $\mathrm{PhD}$ candidates traced in the recent literature is the language challenge. Nonnative speakers consider that language is a barrier to publication in highly recognized journals. According to Hyland (2019), there is a belief among nonnative authors that "editors and referees are prejudiced against them for any non-standard language uses." Nonnative researchers feel that they may be rejected due to their country of origin. This view is proved by Yongyan (2002), who conducted a study about the Chinese researchers' view about publication. The results of this study show that $80 \%$ of the participants believed that they have less chances of publication compared to native researchers. On the other hand, native speakers have better opportunities to publish. Furthermore, the statistical study conducted by Saponsik, et al. (2014) shows that the acceptance rate in 15000 articles is in favor of native rather than non-native speakers.

This shows that English does represent a constraint for non-native researchers in their publication journey. Native speakers are easily able to read the literature of their field and grasp its ideas, which, in turn, increases their chances of publication (Clavero, 2010).

\section{Method}

\subsection{Instrumentation}

As previously mentioned, the current study aims to explore the challenges facing Arab candidates during their PhD programs. Besides, it highlighted the appropriate solutions provided by the participants to minimize the degree of the challenges. Therefore, the researchers directed to use the qualitative approach to fulfill the two given purposes. According to Bengtsson (2016), this approach focuses on obtaining an extensive understanding of the studied phenomena. The qualitative method contained the semi-structured interview questions; the reason beyond selecting this instrument, according to Edwards and Holland (2013), is its contribution to collect massive responses related to the thoughts, actions, and perceptions of the participants.

\subsection{Research Context and Participants}

The study was carried out at EMU in North Cyprus, in April 2019 during the spring semester. This university adopts English Medium of Instruction (EMI) policy. The respondents were six Arab doctoral students from different Arab contexts, as following Algeria, Jordan, Libya, Yemen, and Sudan.

The researchers focused on selecting the participants based on particular standards through employing the judgmental sampling technique (Karatepe, 2013). Therefore, all of the selected participants passed the qualifying exam, and they are working on their articles and their thesis at the same time. Three of them were male and the rest were female. 


\subsection{Data Collection Procedures and Analysis}

As outlined above, the semi-structured interview was applied as an instrument to achieve the study's purposes. It was prepared on the basis of the review related to challenges of doctoral students. Therefore, the interview questions were inspired by the previous conducted studies and its final results. It included two parts, the first related to general information such as the department, country, and gender while the second involved 22 questions categorized into six classes (personal challenges, institutional challenges, financial support, student-supervisor relationship, publication requirement, and language challenge. A clear consent form was produced to the respondents before the interviews to clarify the aims of the study and ensure their confidentiality. Each interview lasted between 15 to 20 minutes.

After collecting the data through using a tape-recorder, the first step was to transcribe the answers into written scripts using a "Word Software Program." The second step was clustering the responses of the interviewees to classify the most frequent responses reported by the respondents. Then, the researchers got themes that enabled them analyze the answers.

\section{Findings}

The results came through using the content analysis method in the interview data. The analysis revealed diversity of difficulties faced Arab participants in a context of EMI. These difficulties were divided into six categories.

\subsection{Personal Challenges}

The participants face varied personal challenges in their way to complete the program. The interview analysis revealed that the common difficulties faced Arab candidates were related to their academic achievement. For instance, their poor knowledge in language skills and research methods cause them a source of anxiety, stress, fear, lack of motivation, and time management

P2 “...sometimes, I faced problems related to my writing...”

P6 “...I met people who don't know how to do a research, so they ended up leaving the university and the program itself..."

P2 “...Sometimes, I have different kinds of negative feelings such as a lack of motivation..."

P5 “...I have feelings such as stress, anxiety, etc., I can't even find a time for myself to be relaxed..."

P6 “...To be honest I have negative feelings as a PhD student, such as anxiety, stress, sometimes even fear..."

However, other participants had positive feelings such as a satisfaction and enjoyment of being doctoral students. For example some mentioned that 
P1 “...Ok, I can tell you my feeling as a PhD student, I enjoy studying here because I like the environment, the place here. I can say I am satisfied with everything right now..."

P3 “...For myself, I am totally satisfied; I am trying to complete my work earlier...”

To avoid these types of challenges, the entire Arab respondents suggested avoiding such personal challenges through avoiding the sources of negative feelings; in other words, students should be equipped with academic skills and good English language to be able to complete their thesis and publish their articles.

P1 “...Based on my experience, I would like to advice students to improve their skills through English courses and they should read a lot of articles..."

\subsection{Institutional Challenges}

Respondents of the current research mentioned that institutional challenges are important factors facing $\mathrm{PhD}$ students. Some of them showed negative views towards courses provided by the institution for the candidates. Other participants stated difficulties related to the availability of materials and instruments used in conducting researches. Besides, a number of respondents stated the need for academic and professional courses that improve students' skills in their fields.

P2 "...The courses should be improved to a great extent especially in both the instruments and materials..."

P4 “... we need professional courses that help us as doctoral students in conducting our research such as academic writing and research methods..."

P5 “...I don't think these courses support the candidates' study. For instance, in my department, there are few numbers of students, and therefore they force us to take these types of courses unfortunately..."

P6 “...we did not take any of courses such SPSS and methodology at PhD It would be nice to have courses such those in this university...."

On the other hand, other participants presented opposite views towards the doctoral program produced by the similar organization in other departments. They showed a degree of satisfaction towards courses they studied. For instance, some participants said:

P1 “...We have courses such as SPSS, so it helps me because you know that I work as research assistant, so these kinds of courses help me a lot in my career..."

P3 “...I think the department offers good courses in my field. I studied two courses related to statistical analysis such as SPSS; it really helped me in my study...."

While there were contradictory views among participants regarding the efficacy of the program provided for candidates, all of them ensured that the institution produced resources and facilities for students. 
P1 “... the institution provided good recourse, like I can access to a number of universities, journals, etc., through our library. I believe the institution offers good facilities for the students...."

P3 “... I think the institution offer good facilities, for example the library has an access to other libraries, so we can always be updated to new researches in different fields of studies. This access helps me a lot in my research through reading and collecting the newly conducted researches..."

P5 “...we have good resources; for example, I can find a number of articles available on the Internet, because the library has a good access..."

\subsection{Financial Support}

Most of the participants were working as research assistants with a full scholarship. Therefore, their responses regarding the impact of the financial situation on their study, life, etc., were to some extent positive.

P3 “... Hopefully, I don't have financial problems affect my research, I am working right now as you can see and I can manage everything right now..."

P4 “... I have a funding support; I am research assistant here, thanks God..."

P5 “... For now, I don't have any financial problems, I got a scholarship and I am research assistance as well..."

Participant 6, on the other hand, said that he/she faced some financial problems due to losing his/her scholarship.

P4 “...I ended up freezing one semester because of that [financial problems]. I used to be research assistant. Then when I left, of course I lost my scholarship, so now I don't have any support..."

\subsection{Student-Supervisor Relationship}

Generally speaking, the student-supervisor relationship is considered, as a critical challenge that might face a number of doctoral candidates. However, in the current EMI context, the analysis revealed that the given parties were to a great extent linked positively. Most of the participants indicated that their supervisors guide, encourage, and support them during their research and thesis writing. For example, some students said:

P1 “...My supervisor guides and supports me, we weekly meet to discuss the topic and evaluate the process of our research..."

P2 “...He/she guides me during my research process, and we always meet face to face to discuss the topic. We usually send emails to each other to determine the date and time for meeting. I can tell fortunately he/she is not always busy and replies me immediately..." 
P6 “.... Well basically I believe I have a positive relationship with my supervisor, because she/he is supportive. I mean she/he does not push me hard, which I believe it is really good. She/he lets me do the work and give me her/his feedback, instead of asking me to do anything. I believe it is better for me, and yes it is a positive relationship...."

Although there were positive findings related to the student-supervisor relationship, respondents produced some recommendations for other colleagues to maintain a promising outcome of the doctoral program, which was selecting their supervisors. Having a supervisor, eager to support, guide, and meet with students on a schedule base, increases their abilities to accomplish their thesis and articles.

P3 “... I would like to recommend other students choosing the good supervisor, building with him/ her a good relationship, and at the end they will be able of getting good results with their research...."

P4 “...For doctoral students, the most important point is to find the suitable supervisor who guides them to reach their goals like publishing a paper with a good citation...."

P5 “...I advise students to select both a supervisor and a co-supervisor. If someone is busy then you can ask the other for help..."

\subsection{Publication Requirement}

Eastern Mediterranean University requires publishing an article in journals indexed in $\mathrm{SSCI} / \mathrm{SCI}$ databases to graduate from $\mathrm{PhD}$. As the $\mathrm{PhD}$ candidates are novice authors who might have never published an article before, publication represents a major challenge for them. Therefore, they might experience a number of difficulties related to the given situation, such as wasting time while waiting for the response letter. For example some participants stated that

P1 “...For the publishing, you know that it mostly depends on the luck to be honest. It is not related to whether you are smart or skilled. That is why I think publication is kind of wasting time..."

P4 “...I am still waiting for their acceptance letters [from the journal] for more than one year..."

Although the publication is a main challenge for Arab candidates, the results they get in publishing their work are of great importance for them as publication will help them with future work opportunities.

“... I believe publishing paper, particularly in SSCI, will help you finding a good job later..."

On the other hand, some participants consider that publication is a significant challenge for them, and the policy should not be restricted to SSCI or SCI indexing. Rather, the published articles should be evaluated based on their significance and contribution rather than the 


\section{Macrothink}

Journal of Studies in Education

ISSN 2162-6952

2019, Vol. 9, No. 4

journals. Candidates should have flexibility in selecting other advanced journals with high impact factor.

P1 “... I can say that publishing in SSCI/SCI should not be as a requirement for doctoral student, the focus should be on the contribution of your research in your field of study..."

$P 2$ "... I think the university should work on changing this policy, and it should let students select the journal with high impact factor not only SSCI..."

P6 “... As for publishing an article in SSCI, SCI is good to publish there, but it should not be the only option, I feel it is limiting students somehow..."

\subsection{Language Challenge}

Most of the participants consider that they have a problem in English language when writing their thesis or publishing their articles. The main reason was being nonnative speakers of English. According to P5, English prevents him/her from completing the literature review, as it needs a good academic writing skill.

P5 “.... English is not our language. I completed the scientific research process, but I could not write the theoretical part of my thesis. Writing the introduction takes a long time of me by the way...."

Another difficulty the participants face is not receiving enough feedback from their supervisors about their language. The participants either depend on themselves to improve their writing or send it to some language editors.

P1 "I don't get that [feedback about language] from my supervisor, but I get some recommendation related to my topic in general."

P4. "I don't get feedback from my supervisor till now, but my friends send their papers to English language editors."

Nevertheless, some participants consider that it is the responsibility of the $\mathrm{PhD}$ candidates to improve their language before starting the $\mathrm{PhD}$ program.

P3 "Arab doctoral students should be prepared before starting the program."

P4 "Students should improve their language skills before starting the program to avoid this difficulty and saving time."

On the other hand, P1 considers that it is the responsibility of the university to provide the $\mathrm{PhD}$ candidates with supportive English language courses to help the learners improve their academic language skills.

“... The university should provide more supportive English language courses. The courses provided here are not good enough for doctoral students particularly the Arab students to improve their language skills..." 


\section{Discussion}

The current study has examined the challenges of PhD Arab candidates in an EMI context. The results show that the participants face some personal challenges, such as anxiety, stress, lack of motivation, and time management problems. These findings are similar to the ones in the recent literature (Bireda, 2015; Hwang et al, 2015; Kakupa, 2019).

The main reason for these challenges is the lack of academic knowledge in language and methodology, which was also proved by many studies (Bamgboje-Ayodele et al., 2016; Lei $\& \mathrm{Hu}, 2019$; Mouton, 2001; Pyhältö et al., 2012). The two main skills needed for PhD Arab candidates are research methodology and academic English. This coincides with studies in the recent literature (Alfadaa, 2012; Bamgboje-Ayodele et al., 2016; Hyland, 2019; Joma \& Bidin, 2017; Lei \& Hu, 2019). The participants only focused on these two skills rather than other ones due to their importance for their graduation. The need for improving the academic writing and research methodology is of great importance to improve the publication opportunities as publication in an SSCI or SCI journals is a requirement for graduation at EMU. The requirement of publication represents the main concern for the $\mathrm{PhD}$ candidates, which agrees with what Lei and Chuang (2009) have said. The candidates consider that the publication requirement puts a lot of pressure on them, as they need to choose a good topic, construct a suitable methodology, and write academically in order to satisfy the publishing journals. Although the participants believe that this publication will help them a lot in their future career, they believe that they need some preparation before going to publication in prestigious journals. This could be through gaining experience in publishing in non-highly ranked journals, attending conferences, having workshops about publication, and meeting some reviewers and editors in order to immerse them to the world of publication gradually.

English language is still a main challenge for the candidates as they are nonnative speakers of English. This agrees with many other studies (ex. Clavero, 2010; Hyland, 2019; Saponsik, et al., 2014; Yongyan, 2002). The participants even consider that they have to receive much feedback from their supervisors about their academic writing. Yet, supervisors focus on the content part rather than the linguistic one. Therefore, there is a need for a solution for this problem such as having a co-supervisor who is responsible for the academic writing of the candidates.

The positive relationship between the supervisors and supervisees is of great importance for the participants. Choosing the supervisor is a very critical issue for the candidates to graduate; this agrees with the findings of Nesterowicz et al (2019). The financial challenge proves that when $\mathrm{PhD}$ candidates secure a scholarship or a research assistant, they feel much more comfortable in conducting their research successfully as it is the case in the studies of Aziato (2015) and Knight (2019).

The university even needs to support the $\mathrm{PhD}$ candidates with an access to different journals, especially with the ones that are highly ranked in order to read articles and get more of the writing for articles genre. This will help them improve their language skills as well as their publication skills. As Warburton and Macauley (2014) have suggested, the university is 
responsible for supporting the $\mathrm{PhD}$ candidates with open-access to different journals that prepares them to enter the world of publication.

\section{Limitations and Future Directions}

The current study was carried out in the context of EMI to figure out challenges facing Arab doctoral students during their $\mathrm{PhD}$. Moreover, it highlighted suggestions provided by respondents to solve these challenges. Though there was a diversity in results revealed from Arab respondents, some limitations are needed to be reconsidered for future studies.

The first limitation of the study is related to the context; Arab participants were only selected from a specific institution in Cyprus. For further studies, including additional universities at the same context might contribute to explore more difficulties facing Arab students in their $\mathrm{PhD}$ program. The second limitation is linked to the qualitative instrument used (semi-structured interviews) for collecting the data. For future researchers, they may want to select a questionnaire as a quantitative method that allows them to collect specific information from more participants to know whether the results may be generalized to other contexts or not.

\section{References}

Al Fadda, H. (2012). Difficulties in academic writing: From the perspective of King Saud University postgraduate students. English Language Teaching, 5(3), 123-130. https://doi.org/10.5539/elt.v5n3p123

Alavi, M., \& Mansor, S. (2011). Categories of problems among international students in Universiti Teknologi Malaysia. Procedia-Social and Behavioral Sciences, 30, 1581-1587. https://doi.org/10.1016/j.sbspro.2011.10.307

Alkathiri, M., \& and Olson, M. (2018), Perceived challenges facing doctoral students and perceptions of the professoriate, Educate Journal, 18(1), 2-12.

Aziato, L. (2015). Learning from a lived experience of a PhD: A reflexive ethnography of two journeys. International Journal of Higher Education, 4(4), 199-206. https://doi.org/10.5430/ijhe.v4n4p199

Bamgboje-Ayodele, A., Ye, M., Almond, H., \& Sakulwichitsintu, S. (2016). Inside the minds of doctoral students: Investigating challenges in theory and practice. International Journal of Doctoral Studies, 11, 243-267. https://doi.org/10.28945/3542

Barrie, S. (2004). A research-based approach to generic graduate attributes policy. Higher Education Research \& Development, 23, 261-75. https://doi.org/10.1080/0729436042000235391

Bengtsson, M. (2016). How to plan and perform a qualitative study using content analysis. Journal of NursingPlus Open, 2, 8-14. https://doi.org/10.1016/j.npls.2016.01.001

Bireda, A. (2015). Challenges to the doctoral journey: A case of female doctoral students from Ethiopia. Open Praxis, 7(4), 287-297. https://doi.org/10.5944/openpraxis.7.4.243 
Boyce, B., Curtner-Smith, M., \& Sinelnikov, O. (2016). Recruiting, funding, and hiring of doctoral students in physical education teacher education. Quest, 68(4), 394-405. https://doi.org/10.1080/00336297.2016.1234400

Clavero, M. (2010). Awkward wording. Rephrase: linguistic injustice in ecological journals. Trends in ecology \& evolution, 25(10), 552-553. https://doi.org/10.1016/j.tree.2010.07.001

Duffy, J., Wickersham-Fish, L., Rademaker, L., \& Wetzler, E. (2019). Using collaborative autoethnography to explore online doctoral mentoring: Finding empathy in mentor/protégé relationships. American Journal of Qualitative Research, 2(1), 57-76.

Edwards, R., \& Holland, J. (2013). What is qualitative interviewing? A\&C Black.

Harman, G. (2003). International PhD students in Australian universities: Financial support, course experience and career plans. International Journal of Educational Development, 23(3), 339-351. https://doi.org/10.1016/S0738-0593(02)00054-8

Hunter, K., \& Devine, K. (2016). Doctoral students' emotional exhaustion and intentions to leave academia. International Journal of Doctoral Studies, 11, 35-61. https://doi.org/10.28945/3396

Hwang, E., Smith, R., Byers, V., Dickerson, S., McAlistar-Shields, L., Onwuegbuzie, A., \& Benge, C. (2015). Doctoral students' perceived barriers that slow the progress toward completing a doctoral dissertation: A mixed analysis. Journal of Educational Issues, 1(1), 164-190. https://doi.org/10.5296/jei.v1i1.7703

Hyatt, L., \& Williams, P. (2011). 21st Century competencies for doctoral leadership faculty. Innovative Higher Education, 36(1), 53-66. https://doi.org/10.1007/s10755-010-9157-5

Hyland, K. (2019). Participation in publishing: The demoralizing discourse of disadvantage. In Novice Writers and Scholarly Publication (pp. 13-33). Palgrave Macmillan, Cham. https://doi.org/10.1007/978-3-319-95333-5_2

Janta, H., Lugosi, P., \& Brown, L. (2014). Coping with loneliness: A netnographic study of doctoral students. Journal of further and Higher Education,38(4), 553-571. https://doi.org/10.1080/0309877X.2012.726972

Jomaa, N., \& Bidin, S. (2017). Perspectives of EFL doctoral students on challenges of citations in academic writing. Malaysian Journal of Learning and Instruction, 14(2), 177-209. https://doi.org/10.32890/mjli2017.14.2.7

Jones, M. (2013). Issues in doctoral studies-forty years of journal discussion: Where have we been and where are we going? International Journal of Doctoral studies, 8, 83-10. https://doi.org/10.28945/1871

Kakupa, P. (2019). Students' attitudes towards research: A study of graduate education students at a Chinese Normal University. Educational Process: International Journal, 8(2), 97-110. 
Kalaleh, A., Dehnad, A., Arabshahi, S., Hosseini, A., \& Bigdeli, S. (2014). Academic skills for post-graduate students: A choice or a necessity?.Procedia-Social and Behavioral Sciences, 116, 5180-5183. https://doi.org/10.1016/j.sbspro.2014.01.1096

Knight, D., Kinoshita, T., Choe, N., \& Borrego, M. (2018). Doctoral student funding portfolios across and within engineering, life sciences and physical sciences. Studies in Graduate and Postdoctoral Education, 9(1), 75-90. https://doi.org/10.1108/SGPE-D-17-00044

Lei, J., \& Hu, G. (2019). Doctoral candidates' dual role as student and expert scholarly writer: An activity theory perspective. English for Specific Purposes, 54, 62-74. https://doi.org/10.1016/S0883-0355(02)00059-9

Lei, S., \& Chuang, N. (2009). Research collaboration and publication during graduate studies: Evaluating benefits and costs from students' perspectives. College Student Journal, 43(4), 1163-1168.

Li, F., \& Qi, H. (2019). An investigation of push and pull motivations of Chinese tourism doctoral students studying overseas. Journal of Hospitality, Leisure, Sport \& Tourism Education, 24, 90-99. https://doi.org/10.1016/j.jhlste.2019.01.002

Moate, R., Gnilka, O., West, E., \& Rice, K. (2019): Doctoral student perfectionism and emotional well-being. Journal of Measurement and Evaluation in Counseling and Development, 1-11. https://doi.org/10.1080/07481756.2018.1547619

Mouton, J. (2001). How to Succeed in your Masters and Doctoral Studies. Pretoria: Van Schaik Publishers.

Nesterowicz, K., Radicev, S., Fereshtehnejad, S., Peacock, J., \& Nemeslaki, A. (2019). PhD education challenges-doctoral candidates' Perspectives. European Scientific Journal, ESJ, 15(4), 54-65. https://doi.org/10.19044/esj.2019.v15n4p54

Odena, O., \& Burgess, H. (2017). How doctoral students and graduates describe facilitating experiences and strategies for their thesis writing learning process: A qualitative

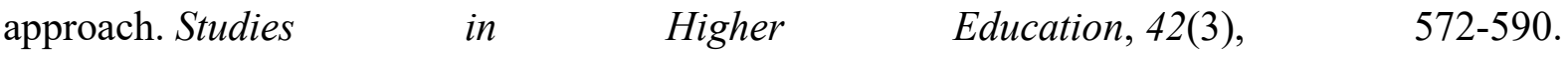
https://doi.org/10.1080/03075079.2015.1063598

Olive, J. (2019). The impact of longitudinal action research on doctoral student retention and degree completion. The Qualitative Report, 24(3), 470-482.

Platow, M. (2012). PhD experience and subsequent outcomes: A look at self-perceptions of acquired graduate attributes and supervisor support. Studies in Higher Education, 37(1), 103-118. https://doi.org/10.1080/03075079.2010.501104

Pyhältö, K., Toom, A., Stubb, J., \& Lonka, K. (2012). Challenges of becoming a scholar: A study of doctoral students' problems and well-being. International Scholarly Research Network Education, 2012, 1-12. https://doi.org/10.5402/2012/9349411

Saposnik, G., Ovbiagele, B., Raptis, S., Fisher, M., \& Johnston, S. C. (2014). Effect of English proficiency and research funding on acceptance of submitted articles to Stroke 
journal. Stroke, 45(6), 1862-1868. https://doi.org/10.1161/STROKEAHA.114.005413

Walton, H., Aquino, M., Talbot, C., \& Melia, C. (2019). A Guide for Psychology Postgraduates: Surviving Postgraduate Study (second edition). The British Psychological Society.

Warburton, J., \& Macauley, P. (2014). Wrangling the literature: Quietly contributing to HDR completions. Australian Academic \& Research Libraries, 45(3), 159-175. https://doi.org/10.1080/00048623.2014.928992

Wisker, G., Morris, C., Cheng, M., Masika, R., Warnes, M., Trafford, V., \& Lilly, J. (2010). Doctoral learning journeys: Final report. Higher Education Academy.

Yongyan, L. (2002). Writing for international publication: The perception of Chinese doctoral researchers. Asian Journal of English Language Teaching, 12, 179-193. 